\title{
Impact and Flexural Strength, and Fracture Morphology of Acrylic Resins With Impact Modifiers
}

\author{
Fernanda Faot*, Leonardo H V Panza, Renata C M Rodrigues Garcia and Altair Antoninha Del Bel \\ Cury
}

Rua Gonçalves Chaves, 457, 2nd floor, Pelotas - RS - Brazil, Zip Code: 96015560 / Faculty of Dentistry, Federal University of Pelotas, Pelotas, RS, Brazil

\begin{abstract}
Objectives: This study evaluated the impact and flexural strength and analyzed the fracture behavior of acrylic resins. Methods: Eighteen rectangular specimens were fabricated of Lucitone 550, QC 20 (both unreinforced acrylic resins), Impact 1500 (extra strength impact), Impact 2000 (high impact) according to the manufacturers' instructions. The impact strength was evaluated in notched specimens $(50 \times 6 \times 4 \mathrm{~mm})$ and flexural strength in unotched $(64 \times 10 \times 3.3 \mathrm{~mm})$, using three-point bending test, as well as, stress at yield, Young modulus and displacement at yield. Fragments from mechanical tests were observed by SEM. Data from impact strength, stress at yield and displacement at yield were analyzed by 1 -way ANOVA and Tukey test $(\alpha=0.05)$. Young modulus values were analyzed by One-way ANOVA and Dunnett T3 multiple comparisons test $(\alpha=0.05)$. Results: Mean values of impact strength and stress at yield values were higher $(P<.005)$ for Impact 2000 while Young modulus was higher $(P<.05)$ for Lucitone 550; Impact 1500 and Impact 2000 showed significant values $(P<.05)$ in the displacement at yield. Impact fractures of the all acrylic resins were brittle. Bending fractures of Lucitone 550 and Impact 2000 were brittle, QC 20 fractures were ductile and Impact 1500 showed brittle $(75 \%)$ and ductile (25\%) fractures. Conclusion: Within the limitations of this study, the Impact 2000 showed improved mechanical properties with high capacity of stress absorption and energy dissipation before the fracture.
\end{abstract}

Keywords: Acrylic resins, high impact, impact strength, stress at yield, fracture morphology, fracture microstructure, deformation behavior, fracture process, brittle fracture, ductile fracture, cross-linking agents.

\section{INTRODUCTION}

Denture fracture is a problem commonly encountered by removal prosthodontics wearers and dentists, and it is related to material properties, technical features, and stresses that dentures are subject to in service or when they are dropped. In addition, considering the recommendations of the McGill Consensus Statement on overdentures [1], suggesting implant supported overdentures be the standard of care for mandibular edentulous patients and the concomitant increase in the use of overdentures, the use of acrylic resins with better quality is imperative [2].

As a result, new and stronger acrylic resins have been developed. The modifiers introduced in acrylic denture composition include co-polymers, cross-linking agents [3-5] and rubber substances in the form of butadiene styrene [6-8]. Therefore, although high-impact denture base resins have been on the market for over 30 years ago, manufactures claim that these polymers are stronger and tougher because this type of acrylic resin is able to absorbing greater amounts of energy at a higher strain rate before fracture [9].

There is some evidence, however, that the incorporation of rubber has not been entirely successful because it can have detrimental effects on the elasticity modulus and hence the rigidity of the denture base [8]. Furthermore, the clinical

*Address correspondence to this author at the Rua Goncalves Chaves, 457 , 2nd floor, Pelotas - RS - Brazil, Zip Code: 96015560 / Faculty of Dentistry, Federal University of Pelotas, Pelotas, RS, Brazil; Tel: +55 53 32226690; Fax: +55 53 32226690; E-mails: fernanda.faot@ufpel.tche.br, fernanda.faot@gmail.com and laboratorial use of this type of acrylic resin has been limited by its high cost compared with conventional heatcured resin. In addition, it has been shown that the high concentrations of cross-linking agents had little effect on the mechanical properties of dough-molded acrylic resins, with exception of flexural modulus [5].

Therefore, it is important to know about the mechanical aspects of high impact acrylic resins, since there is little information about the effect of adding cross-linking and rubber incorporation in acrylic resin. The effects of these additives on toughening, microstructure and deformation behavior under the impact and flexural tests is also unknown.

The aim of this study was to determine the impact and the flexural strength of two acrylic resins with impact modifiers and compare them with conventional unreinforced denture base acrylic resins. Moreover, the stress at yield, Young modulus and displacement at yield were evaluated and the fracture processes were analyzed by stress-displacement graph. The acrylic resin microstructures in the region of fracture were also examined.

\section{MATERIALS AND METHODS}

The acrylic resins used in this study are listed in Table $\mathbf{1 .}$

Eighteen rectangular specimens of each acrylic resin, measuring $50 \times 6 \times 4 \mathrm{~mm}$ and $64 \times 10 \times 3.3 \mathrm{~mm}$ were prepared for impact and flexural strength tests, respectively. Metal master patterns were individually invested with high-viscosity silicone (Zetalabor; Zermack S.p.A, Badia Polesine, Rovigo, Italy) and used to fabricate the specimens. Patterns were in- 
Table 1. Acrylic Resins Used in this Study

\begin{tabular}{|c|c|c|c|c|}
\hline \multirow{2}{*}{ Acrylic Resins } & \multicolumn{2}{|c|}{ Chemical Composition } & \multirow{2}{*}{ Polymerization Cycles } & \multirow{2}{*}{ Manufacturer } \\
\hline & Powder & Liquid & & \\
\hline Lucitone 550 & $\begin{array}{l}\text { Methyl methacrylate (methyl-n- } \\
\text { butyl) co-polymer, benzoyl perox- } \\
\text { ide, mineral pigments. }\end{array}$ & $\begin{array}{l}\text { Methyl methacrylate monomer, ethylene } \\
\text { glycol dimethacrylate (EGDMA) as cross- } \\
\text { linking agent, hydroquinone. }\end{array}$ & $\begin{array}{l}\text { Water bath }-9 \text { hours at } \\
\qquad 74^{\circ} \mathrm{C}\end{array}$ & $\begin{array}{l}\text { Dentsply Interna- } \\
\text { tional Inc., Chi- } \\
\text { cago, Ill, USA }\end{array}$ \\
\hline QC20 & $\begin{array}{l}\text { Methyl methacrylate (methyl-n- } \\
\text { butyl) co-polymer, benzoyl perox- } \\
\text { ide, atoxic pigments }\end{array}$ & $\begin{array}{l}\text { Methyl methacrylate monomer, ethylene } \\
\text { glycol dimethacrylate (EGDMA) as cross- } \\
\text { linking agent, terpinolene, N-N dimethyl } \\
\text { p-toluidine, hydroquinone. }\end{array}$ & $\begin{array}{l}\text { Boiling water }-100^{\circ} \mathrm{C} \text { for } \\
20 \mathrm{~min}\end{array}$ & $\begin{array}{l}\text { Dentsply Interna- } \\
\text { tional Inc., Chi- } \\
\text { cago, Ill, USA }\end{array}$ \\
\hline Impact 2000 & $\begin{array}{c}\text { Rubber-based copolymer, nuisance } \\
\text { dust, benzoyl peroxide, cadmium } \\
\text { pigments }\end{array}$ & $\begin{array}{l}\text { Methyl methacrylate monomer, ethylene } \\
\text { glycol dimethacrylate (EGDMA) as cross- } \\
\text { linking agent. }\end{array}$ & $\begin{array}{l}\text { Water bath }-9 \text { hours at } \\
\qquad 74^{\circ} \mathrm{C}\end{array}$ & $\begin{array}{l}\text { Bosworth Com- } \\
\text { pany, Ill, USA }\end{array}$ \\
\hline Impact 1500 & $\begin{array}{l}\text { Methyl methacrylate, particulate } \\
\text { NOC (non-cadmium), residual } \\
\text { monomer, titanium dioxide }\end{array}$ & $\begin{array}{l}\text { Methyl methacrylate monomer, alkyldi- } \\
\text { methacrylate as cross-linking agent. }\end{array}$ & $\begin{array}{l}\text { Boiling water }-100^{\circ} \mathrm{C} \\
\quad \text { for } 20 \mathrm{~min}\end{array}$ & $\begin{array}{l}\text { Bosworth Com- } \\
\text { pany, Ill, USA }\end{array}$ \\
\hline
\end{tabular}

vested in Type III dental stone (Herodent Soli Rock; Vigodent, Rio de Janeiro, Brazil) in metal dental flasks (Uraby; DLC, São Paulo, Brazil). Acrylic resins were mixed in accordance with the manufacturers' instructions and packed into the silicone molds at dough stage [10].

To polymerize Lucitone 550 and Impact 2000 acrylic resins, the flasks were placed in a polymerizing unit (Termotron P-100; Termotron Equipamentos Ltd, Piracicaba, Brazil) filled with water at $74^{\circ} \mathrm{C}$ water for 9 hours. Flasks containing QC-20 and Impact 1500 acrylic resins were immersed in boiling water for 20 minutes. All the acrylic resins were polymerized according to the cycles recommend by the manufactures. Next, all flasks were allowed to bench cooling for 2 hours. Specimens were deflasked, and each specimen was trimmed and finished, using abrasive papers (320, 400 and 600-grit, Carbimet; Buehler, Lake Bluff, Ill) in a polishing machine (Model APL-4; Arotec, Sao Paulo, Brazil). After that, the specimens were ultrasound cleansed (Thornton $\mathrm{T}$ 740, Thornton-Inpec Eletrônica LTDA, Vinhedo, Brazil) for $20 \mathrm{~min}$ and then immersed in distilled water at $37^{\circ} \mathrm{C}$ for $48 \pm$ 02 hours before testing.

\section{Impact Strength Test}

Impact strength test was performed according to ISO standard 1567:1999/Amd.1:2003(E) [11]. A type V notch was cut in the middle of each specimen using a milling machine (Model FNGJ32, INTOS Ltd., Czech Republic) and a universal milling tool (Model 1322, $45^{\circ}$ double angle; Sandvik Coromant, Sweden). The depth was $1.2 \pm 0.1 \mathrm{~mm}$ leaving a residual depth beneath the notch of $4.8 \pm 0.1 \mathrm{~mm}$ and the notch base radius of $0.25 \pm 0.05 \mathrm{~mm}$ (Fig. 1A).

The impact strength was evaluated using plastic impact test machine (AIC - EMIC, São José dos Pinhais, Paraná, Brazil) using the Charpy method with a pendulum of $0.5 \mathrm{~J}$, in which the specimens were horizontally positioned, with a distance of $40 \mathrm{~mm}$ between the 2 fixed supports (Fig. 1B).

\section{Flexural Strength Test}

Flexural strength test was performed by the 3-point bending test using a universal testing machine (Instron Model 4467, Instron Industrial Products, PA, USA) calibrated with a $500 \mathrm{kgf}$ load cell and a crosshead speed of $5 \mathrm{~mm} / \mathrm{min}$. The flexural testing device consisted of a central loading plunger

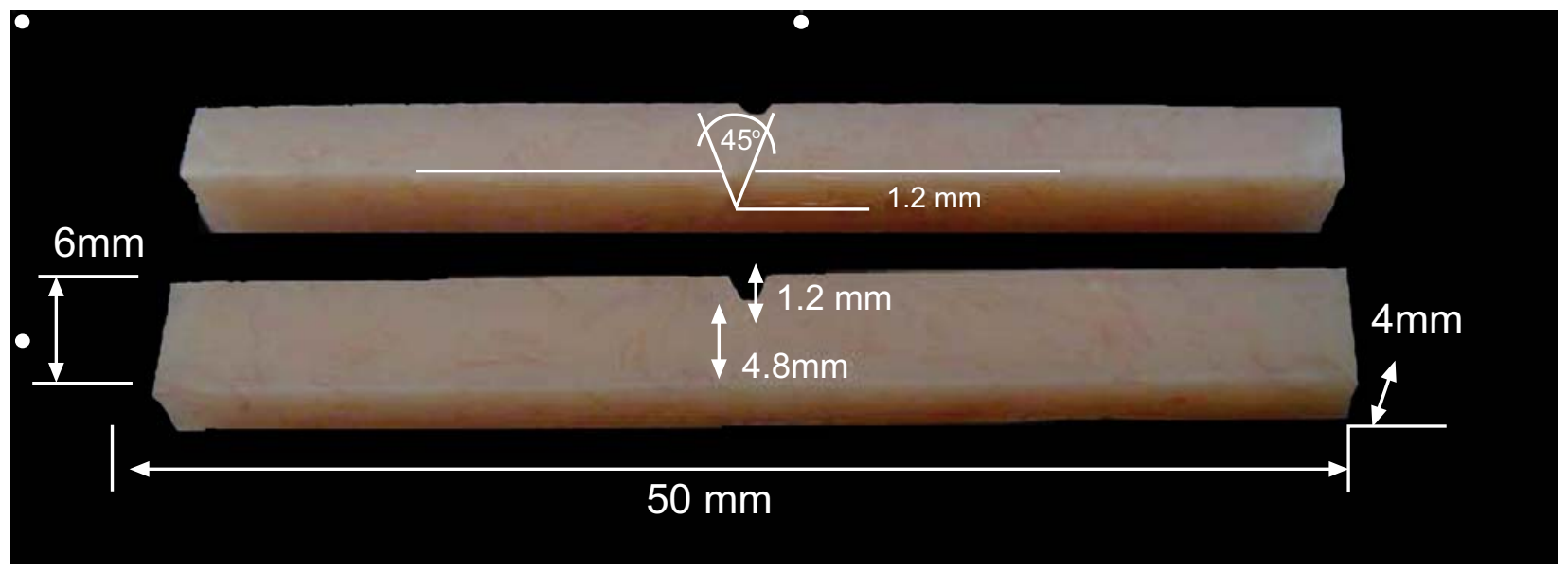

Fig. (1A). Type V notch diagram. 


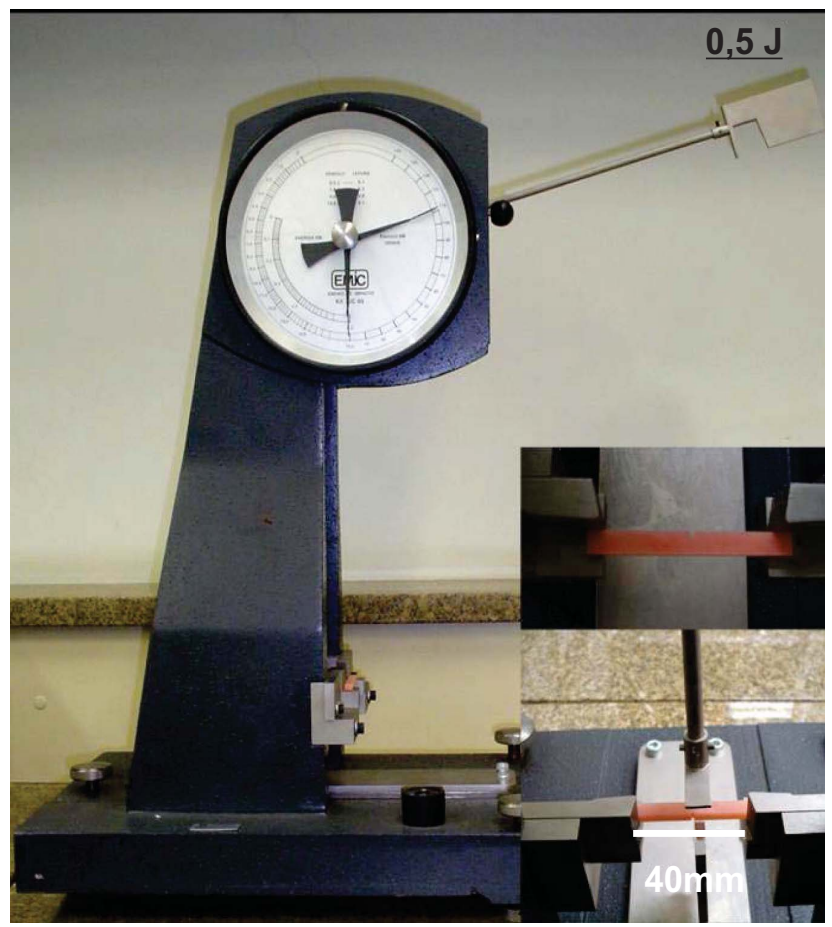

Fig. (1B). Impact strength test by Charpy method.

and 2 polished cylindrical supports, $3.2 \mathrm{~mm}$ in diameter and $10.5 \mathrm{~mm}$ long. The distance between the centers of the supports was $50 \mathrm{~mm}$. The compressive force was applied perpendicular to the center of the specimens until a deviation of the load-deflection curve and the fracture of specimen occurred (Fig. 2). The stress at yield, Young modulus and displacement at yield of the specimens were recorded and the stress-displacement graph was evaluated.

\section{Fracture Analysis}

The fractures of the specimens broken by both the impact and the three point bending tests were classified as brittle or ductile by visual inspection; when the fragments of specimens fractured could be repositioned at the fractured line presenting a smooth surface, the fractures were classified as brittle. Adversely, those presenting plastic deformation, exhibiting rough and jagged sufaces were recorded as ductile [12]. Scanning electron microscopy (SEM; LEO $435 \mathrm{VP}$, Carl Zeiss SMT, Oberkochen, Germany) was used to characterize the fracture surface microstructure around the crack tips of the specimens. A $5 \mathrm{~mm}$ slice was sectioned from the border of the fractured under water-cooling using diamond-

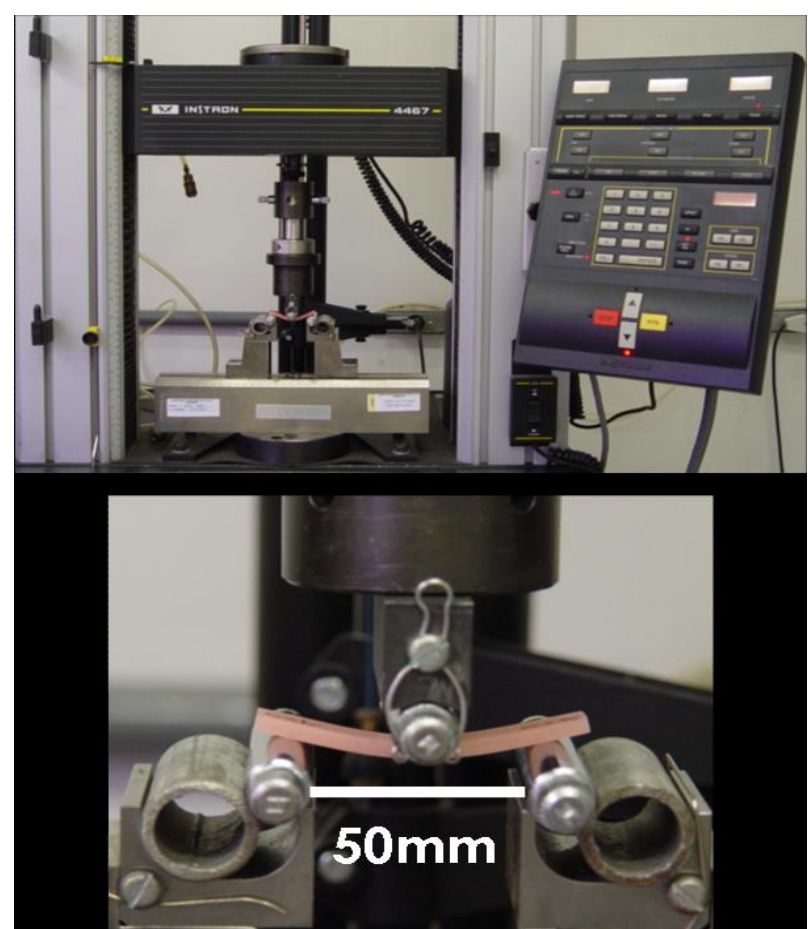

Fig. (2). Action of compressive force in the flexural strength test.

coated disc at $200 \mathrm{rpm}$ in a precision saw (ISOMET 1000; Buhler, Lake Bluff, Ill). SEM-photomicrographs of impact specimens were taken at $100 \times$ magnification and those from three-point bending specimens were taken at $1000 \times$ magnification.

\section{Statistical Analysis}

The statistical analyses were done using SAS software (SAS Institute Inc., version 9.0, Cary, NC) with the significance level fixed at $5 \%$. As impact strength data violated the assumptions of equality of variances and normal distribution of errors, they were transformed into $\log _{10}(\mathrm{X})$ before they were analyzed by One-way ANOVA. Tukey HSD test was also applied to compare impact strength, stress at yield and displacement at yield, and Dunnet T3 test to compare the Young modulus.

\section{RESULTS}

Mean values of the impact strength (J), stress at yield $(\mathrm{MPa})$, Young modulus ( $\mathrm{MPa}$ ) and displacement at yield $(\mathrm{mm})$ are presented in Table 2 . It was verified that the impact

Table 2. Impact Strength (J), Stress at Yield (MPa), Young Modulus (MPa), Displacement at Yield (mm) of Denture Base Materials (Means \pm SD; $\mathbf{n}=18$ )

\begin{tabular}{|c|c|c|c|}
\hline Acrylic Resin & Impact Strength & Stress at Yield & Young Modulus \\
\hline \hline Lucitone 550 & $1.0 \pm 0.12 \mathrm{a}$ & $86.3 \pm 7.5 \mathrm{a}$ & $2.500 \pm 204.5 \mathrm{a}$ \\
\hline QC 20 & $1.0 \pm 0.04 \mathrm{a}$ & $35.3 \pm 7.3 \mathrm{~b}$ & $1.200 \pm 190.9 \mathrm{~b}$ \\
\hline Impact 2000 & $2.4 \pm 0.31 \mathrm{~b}$ & $97.3 \pm 4.8 \mathrm{c}$ & $2.100 \pm 149.3 \mathrm{c}$ \\
\hline Impact 1500 & $1.0 \pm 0.06 \mathrm{a}$ & $56.9 \pm 6.3 \mathrm{~d}$ & $1.400 \pm 113.0 \mathrm{~d}$ \\
\hline
\end{tabular}

Means followed by distinct letters are statistically different at the $5 \%$ level of significance. 


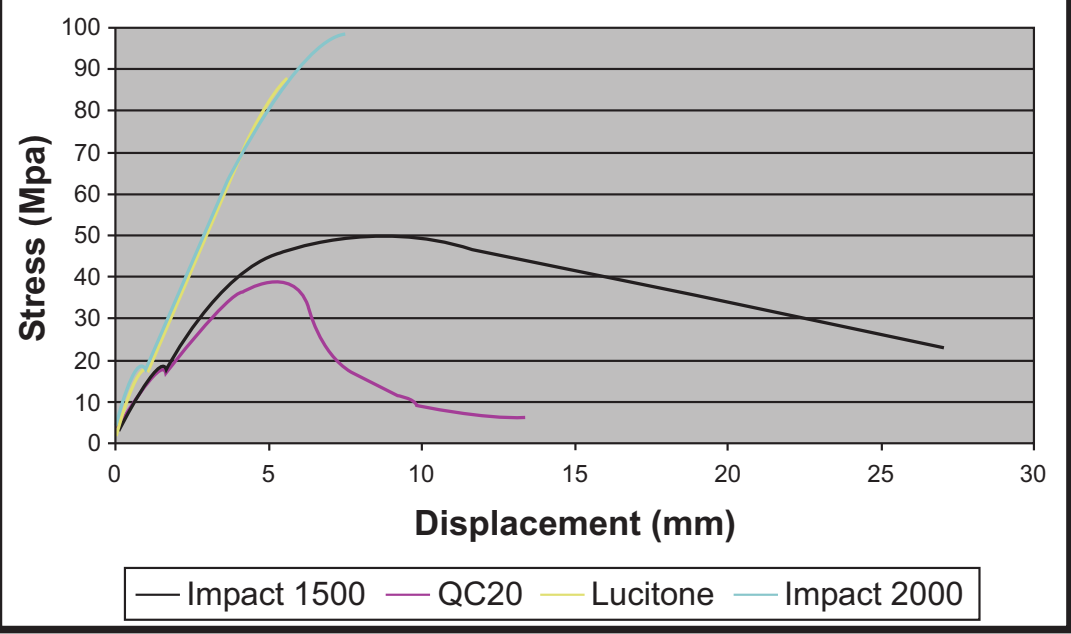

Fig. (3). Graph of Stress-Displacement curves.

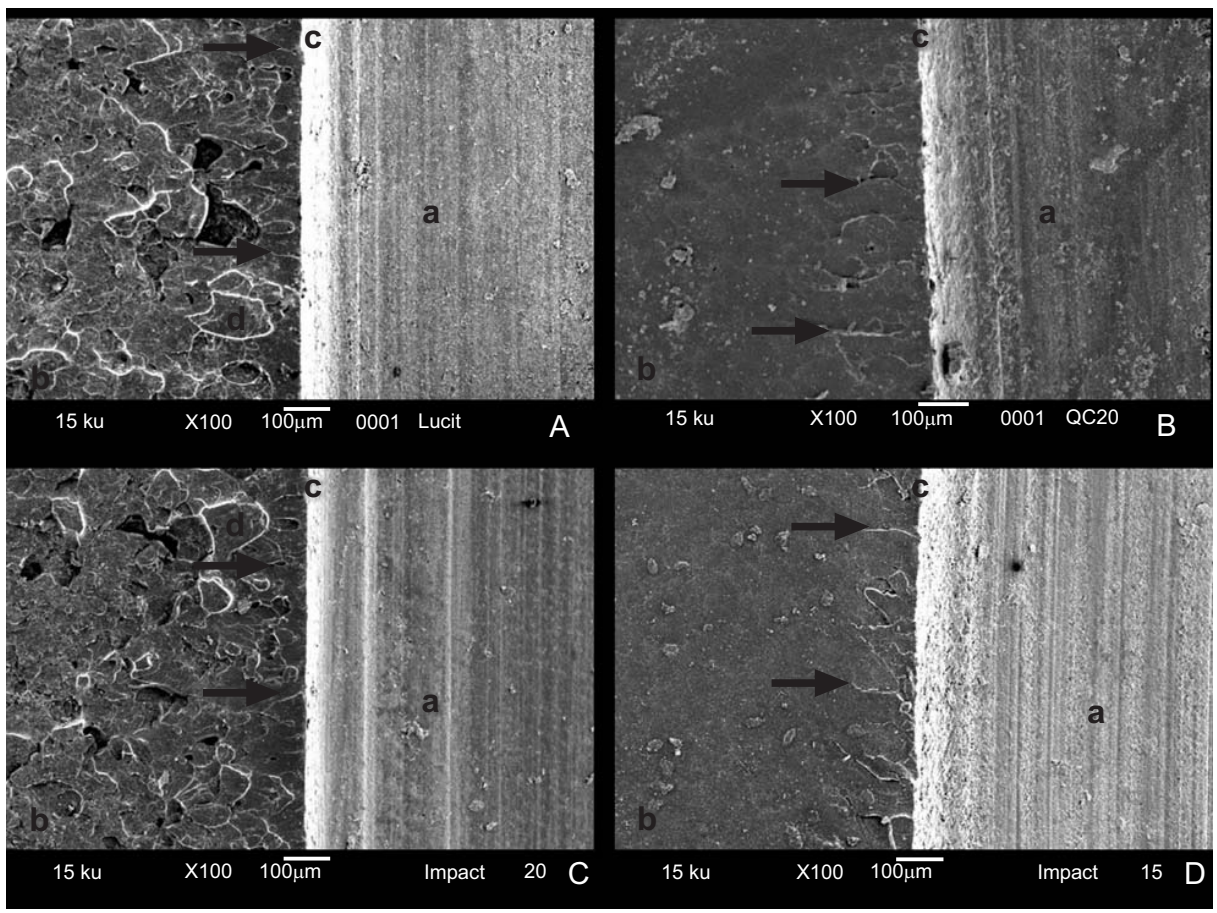

Fig. (4). SEM of impact strength specimens. A. Lucitone 550 resin, B. QC20 resin, C. Impact 2000 resin and D. Impact 1500 resin. a. notch surface, $\mathbf{b}$. fracture surface, $\mathbf{c}$. notch-fracture junction, d. granular structure. Black arrows indicate the striations.

strength value was significantly higher $(P<0.05)$ only for Impact 2000 acrylic resin. Significant differences $(P<0.05)$ were found in the stress at yield for all acrylic resins and Impact 2000 specimens showed the highest value.

With regarding to the Young modulus, significant differences $(P<0.05)$ were also observed for the studied acrylic resins, with higher values for Lucitone 550. Displacement at yield values were significantly higher $(P<0.05)$ for Impact 2000 and Impact 1500 acrylic resin.

The impact test specimens exhibited brittle fractures for all acrylic resins. For the flexural strength test, however, Impact 2000 and Lucitone 550 resins exhibited brittle fractures. QC 20 resin showed ductile fractures and Impact 1500 resin presented 16 ductile and 4 brittle fractures.
Fracture processes and deformation behavior of acrylic resins showed a significant right shift of the plots (Fig. 3). Lucitone 550 and Impact 2000 acrylic resins showed a typical brittle failure behavior, with a low percentage of deformation $(0.002 \%$ and $0.003 \%$ respectively), exhibiting only elastic deformation. QC20 and Impact 1500 presented ductile failures with lower stress concentration at yield values and higher percentage of deformation $(0.032 \%$ and $0.0105 \%$ respectively), exhibiting elastic and plastic deformations during the fracture process.

SEM observations of impact fractures showed that the microstructure of the deformed regions was similar in Impact 2000 and Lucitone 550 (Fig. 4A-C), presenting a rough surface with grain microstructure, with high density and fine striations close to the notch that dissipated into the polymeric 


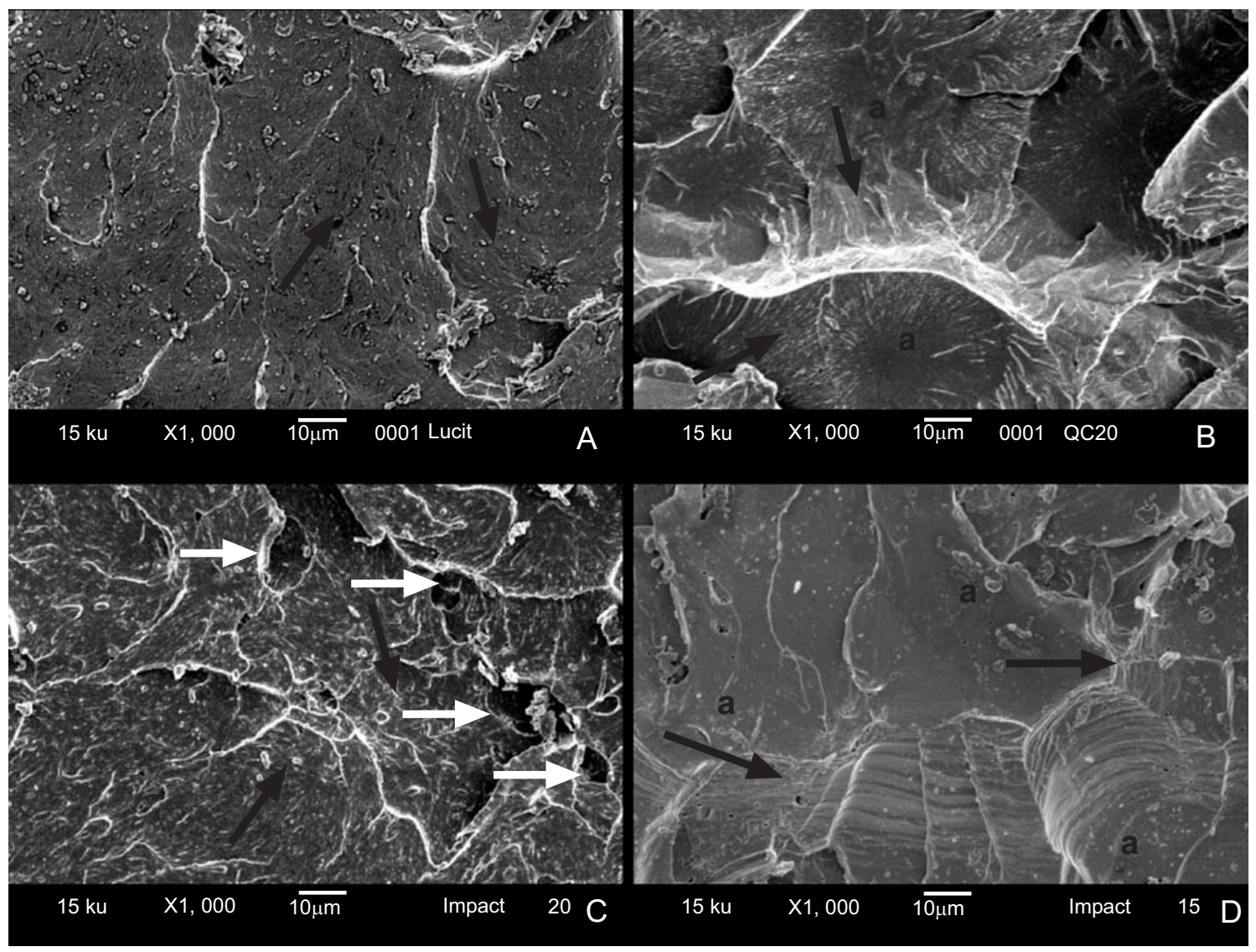

Fig. (5). SEM of flexural strength specimens. A. Lucitone 550 resin, B. QC20 resin, C. Impact 2000 resin and D. Impact 1500 resin. a. Stepped surface and granules microstructure. Black arrows indicate the striations. White arrows show where the rubber particles were attached, and the delimitation indicates that they detached from the PMMA matrix.

matrix. In the QC20 and Impact 1500, a smooth surface could be observed and the striations were more concentrated near to the notch (Fig. 4B-D). On the other hand, the threepoint bending fractures showed distinct microstructures for the acrylic resins studied. Although, Lucitone 550 and Impact 2000 exhibited compact and organized surface fractures (Fig. 5A-C), it was observed that Lucitone 550 exhibited fiber morphology orientated and uninterrupted with low density and short striations while Impact 2000 disorientated fiber morphology was observed. QC20 and Impact 1500 presented disorganized and stepped fracture surfaces (Fig. 5BD). The microstructure revealed the presence of crazing shown by interrupted fiber morphology with longer disorientated high density striations.

\section{DISCUSSION}

Acrylic resin denture fracture continues to be a problem and several attempts have been made to improve the mechanical properties of denture base material. One approach is to have PMMA material strengthened and toughened by chemically modifying conventional heat acrylic resin by adding rubber graft co-polymer or cross-linking agents.

In this study, the high strength denture base acrylic resin, Impact 2000 exhibited the best results for impact and flexural strength, the impact strength being 2.4 times higher than the other acrylic resins studied, as was expected. As mentioned by Jagger et al. (2002) [8], however, it is not possible to discuss the reinforcement mechanisms of this acrylic resin, since its exact constituents are not known. Nevertheless, it is known that addition of rubber in "high impact" denture base resins, in the form of acrylate terminated butadiene styrene block copolymer, produces improved impact strength since this agent (macromers) is able of causing dispersion of the cracks [13].

The other three acrylic resins studied showed the same impact strength values, around 1.0J, irrespective of the polymerization time used.

Moreover, it was observed that Impact 2000 showed significantly and higher values for stress at yield followed by the conventional acrylic resin Lucitone 550 and both were polymerized for a long time by water bath. In contrast, QC20 and Impact 1500, which were polymerized for a short period in boiling water showed the lowest values.

The Young modulus of each acrylic resin was significantly different from the other, with Lucitone 550 exhibiting the highest values $(2.500 \pm 204.5 \mathrm{MPa})$. However, acrylic resins polymerized for a short time in boiling water showed the lowest values, almost half that of the first mentioned. These findings are in agreement with those found by Stafford et al. (1980) [14] who showed that unreinforced acrylic resin had higher fatigue life values in comparison with some reinforced polymers. 
Therefore, these results and those of the stress at yield could be attributed to the polymerization cycle. It has been shown that acrylic resins polymerized for longer periods of time provide polymers with high packing density, better interchain force and polymeric chain arrangements, resulting in acrylic resins with improved mechanical and viscoelastic properties $[5,15,16]$.

On the other hand, the higher values of the impact strength showed by Impact 2000 was improved at the expense of the Young modulus, producing a denture base with a different brittle behavior, indicating decreased ability of the polymer to flow [14]. Probably, alterations in the relaxation behavior generated by the rubber chains sections [9] could be responsible for effects on the intermolecular forces (molecular structure) affecting the chain stiffness [15] in the "high impact acrylic resin".

Considering the displacement at yield values, no significant differences were found between Impact 2000 and Impact 1500 . Both acrylic resins were able to dissipate the crack development slowly through the poly(methylmethacrylate), possibly by different mechanisms. It is known that the rubber reinforced acrylic resin decelerates crack propagation throughout an interpenetrating network of rubber and poly(methylmethacrylate) [13] and this could happen with Impact 2000. Although Impact 1500 does not present rubber reinforcement, its crosslink agent alkyldimethacrylate could be influenced by the polymerization temperature, which could limit the geometry of the polymer network or the unreacted cross-linking agent in the form of a residual monomer, or pendant chains could act as a plasticizer [17].

Stress-displacement curve analyses (Fig. 3) of the acrylic resins showed different fracture toughness, based on the relaxation behavior, which varied in accordance with polymerization cycles. Lucitone 550 and Impact 2000 resin showed similar curves under stress intensity, in accordance with the theory of linear elastic fracture mechanics [18] for brittle fracture. However, Lucitone 550 was brittler than Impact 2000 and started to crack before it. This probably happened because of the presence of rubber particles around the matrix polymer in Impact 2000. Differently, QC20 and Impact 1500 resins exhibited curves with ductile fracture characteristics; crack initiation and plastic deformation also differed between these resins.

Regarding to fracture process results, it is important to consider that the analyses of the toughness behavior of acrylic resin containing alkyldimethacrylate, as impact modifier, can have favorable clinical implications. The ductile fracture process and viscoelastic/relaxation ability of this material seems to be interesting to implant supported overdentures when these prosthesis are submitted to flexural loads by the masticatory forces.

The effects of the impact fracture process on the acrylic resin microstructures observed in the SEM-photomicrographs showed a true network polymer structure with the presence of homogeneous particles for Lucitone 550 and Impact 2000 resins (Fig. 4A-C) while QC20 and Impact 1500 , showed a smooth and flat microstructure with some disoriented striations (Fig. 4B-D).
SEM observation of the three point bending fractures showed that Impact 2000 (Fig. 5C) was rougher than Lucitone 550 (Fig. 5A), which implies that massive deformation of the PMMA matrix occurred. Furthermore, it seems that the rubber particles in the Impact 2000 resin did not adhere well to the PMMA matrix. These findings are in agreement with those observed by Cho et al. (1998) [7] in his study about toughening behavior of rubber modified PMMA, in which it was observed that the rubber particles were detached from the PMMA matrix and only part of the rubber particles were connected to the matrix. This is a reason for the brittle behavior and the unexpected low deformation $(0.003 \%)$ by the multiple crazing in Impact 2000.

QC20 and Impact 1500, which exhibited a slower fracture process, had greater massive deformation (Fig. 5B-D) and worst microstructure characteristics, evidencing that these materials did not transfer the stress far away from the crack, possibly because of their low Young modulus and low stress at yield .The micro structural differences between them, related to grain size, density, and striation lengths and thicknesses, could be explained by their different crosslinked matrixes [19, 20], since Impact 1500 contains alkyldimethacrylate, and QC20 contains ethylene glycol dimethacrylate.

The fact of the mechanical tests have not been performed in a wet conditions similar to the oral cavity could be considered as a limitations of this in vitro study. For better understanding the fracture and deformation mechanisms future researches about the effects of the residual monomer content and the viscoelastic properties on the fracture process and microstructure of acrylic resins could be performed. Furthermore, as the alkyldimethacrylate could be responsible for a ductile fracture behavior and higher results regarding to deflection, a study of its incorporation in a rubber reinforcement polymer could be clarify if the cross-linking agents will be able to alter the fracture process improving the mechanical properties of the rubber polymers.

Also, variables found in the clinics, such as complex shape of dentures and different thickness of baseplates can contribute for decreasing of the mechanical properties described in this studied.

\section{CONCLUSION}

Within the limits of this investigation, it seems that there are advantages to using acrylic resin with rubber incorporation in preference to unreinforced conventional acrylic resins, since its formulation has properties comparable with those of the best proprietary materials, and it meets the requirements of impact strength with minimal decrease in Young modulus.

\section{REFERENCES}

[1] Feine JS, Carlsson GE, Awad MA, et al. The McGill consensus statement on overdentures. Mandibular two-implant overdentures as first choice standard of care for edentulous patients. Montreal, Quebec, May 24-25, 2002. J Oral Maxillofac Implants. 2002; 17(4): 601-2.

[2] Meng TR Jr, Latta MA. Physical properties of four acrylic denture base resins. J Contemp Dent Pract 2005; 6: 93-100.

[3] Caycik S, Jagger RG. The effect of cross-linking chain length on mechanical properties of a dough-molded poly(methylmethacrylate) resin. Dent Mat 1992; 8: 153-7. 
[4] Uzun G, Hersek N. Comparison of the fracture resistance of six denture base acrylic resins. J Biomater Appl 2002; 17: 19-29.

[5] Memon MS, Yunus N, Razak AA. Some mechanical properties of a highly cross-linked, microwave-polymerized, injection-molded denture base polymer. Int J Prosthodont 2001; 14: 214-8.

[6] Rodford R. The development of high impact strength denture-base materials. J Dent 1986; 14: 214-7.

[7] Cho KYJ, Park CE. The effect of rubber particle size on toughening behaviour of rubber-modified poly(methylmethacrylate) with different test methods. Polymer 1998; 39: 3073-81.

[8] Jagger DC, Jagger RG, Allen SM, Harrison A. An investigation into the transverse and impact strength of "high strength" denture base acrylic resins. J Oral Rehabil 2002; 29: 263-7.

[9] Rodford RA. Further development and evaluation of high impact strength denture base materials. J Dent 1990; 18: 151-7.

[10] Del Bel Cury AA, Rached RN, Ganzarolli SM. Microwave-cured acrylic resins and silicone-gypsum moulding technique. J Oral Rehabil 2001; 28: 433-8.

[11] International Organization for Standardization. ISO 1567:1998. Dentistry: denture base polymers. Geneva, Switzerland 1998.

[12] Faot F, Costa MA, Del Bel Cury AA, Rodrigues Garcia RCM. Impact strength and fracture morphology of denture acrylic resins. J Prosthet Dent 2006; 96: 367-73.
[13] Jagger DC, Harrison A, Jandt KD. The reinforcement of dentures. J Oral Rehabil 1999; 26: 185-94.

[14] Stafford GD, Huggett R, Causton BE. Fracture toughness of denture base acrylics. J Biomed Mater Res 1980; 14: 359-71.

[15] Brown N. Yield behavior of polymers. In: Brostow W, Corneliussen RD, Eds. Failure of plastics. New York: Hanser 1986; pp. 110-8.

[16] Smith LT, Powers JM, Ladd D. Mechanical properties of new denture resins polymerized by visible light, heat, and microwave energy. Int J Prosthodont 1992; 5: 315-20.

[17] Harrison A, Huggett R, Jagger RC. The effect of a cross-linking agent on the abrasion resistance and impact strength of an acrylic resin denture base material. J Dent 1978; 6: 299-304.

[18] Hargreaves AS. The effect of the environment on the crack initiation toughness of dental poly(methyl methacrylate). J Biomed Mater Res 1981; 15: 757-68.

[19] Kusy RP, Turner DT. Fractography of poly(methyl methacrylates). J Biomed Mater Res 1975; 9: 89-98.

[20] Vallittu PK. Fracture surface characteristics of damaged acrylicresin-based dentures as analysed by SEM-replica technique. J Oral Rehabil 1996; 23: 524-9.

(C) Faot et al.; Licensee Bentham Open.

This is an open access article licensed under the terms of the Creative Commons Attribution Non-Commercial License (http://creativecommons.org/licenses/by-nc/3.0/) which permits unrestricted, non-commercial use, distribution and reproduction in any medium, provided the work is properly cited. 